\title{
Migración y desarrollo en las sociedades avanzadas. Una mirada desde América Latina
}

\author{
Alejandro I. Canales \\ Universidad de Guadalajara, Guadalajara, México. Email: acanales60@gmail.com
}

\begin{abstract}
Resumen: El debate sobre la relación entre migración y desarrollo ha estado hegemonizado por la visión que los países receptores y organismos internacionales tienen de ella. En la última década se ha consolidado el análisis de la migración internacional desde el enfoque de la seguridad nacional de los países receptores. En estos años han tomado fuerza las posiciones políticas conservadoras que sustentan la criminalización de la migración indocumentada, y que impulsan diversas políticas de control inmigratorio. Frente a esta mirada, se plantea pasar del enfoque del llamado “management of migration”, a uno de la así llamada “gobernanza de la migración”, que busca incluir los derechos e intereses de los migrantes en el centro del debate. Lo que nos interesa mostrar en este trabajo, es que la perspectiva hegemónica ha llevado a invisibilizar tanto las condiciones económicas y demográficas de los países de destino que sustentan y dan espacio a la inmigración, así como el aporte de estos inmigrantes a la dinámica de la economía y de la reproducción de estas sociedades. Nos interesa mostrar estimaciones sobre el aporte de los inmigrantes latinoamericanos a la dinámica económica y social de los Estados Unidos y España, principales destino de este flujo migratorio. Para ello, nos sustentaremos en el análisis de datos cuantitativos e información proveniente de estadísticas oficiales de ambos países y la elaboración de un modelo de análisis que busca ofrecer una visión comprehensiva del papel de la migración internacional en la reproducción social, demográfica y económica en las sociedades avanzadas.
\end{abstract}

Palabras clave: migración y desarrollo, demografía, migración latinoamericana, Estados Unidos, España.

\section{Migration and development in advanced societies. A view from Latin America}

\begin{abstract}
The discussion on the relationship between migration and development has been hegemonaized by the perspective of host countries and international organizations. In the past decade it has established the analysis of international migration from the perspective of national security in host countries. In these years have taken hold conservative political positions that support the criminalization of undocumented migration, and driving various immigration control policies. Given this view, we propose to move on from the approach of the "management migration", to one of the so-called "migration governance," which seeks to include the rights and interests of migrants in the center of the debate. What we want to show in this paper, is that the hegemonic perspective has invisiblized both economic and demographic conditions of the destination countries that support and give space to immigration, and the contribution of these immigrants to the dynamics of the economy and reproduction of these societies. We expose estimates of the contribution of Latin
\end{abstract}


American immigrants to the economic and social dynamics of the United States and Spain, the main destination of this migration flow. For this, we provide sustenance in the analysis of quantitative data and information from official statistics of both countries and the development of an analytical model that seeks to provide a comprehensive view of the role of international migration on social reproduction in demographic and economic advanced societies.

Key words: migration and development, demography, Latin American migration, United States, Spain.

\section{Migração e desenvolvimento nas sociedades avançadas. Uma visão da América Latina}

Resumo: O debate sobre a relação entre migração e desenvolvimento tem sido sob a hegemonia da visão que os países beneficiários e as organizações internacionais têm dele. Na última década estabeleceu a análise da migração internacional do ponto de vista da segurança nacional dos países beneficiários. Nos anos recentes assumiu cargos políticos conservadores que apoiam a criminalização da migração irregular, e dirigindo diversas políticas de controle migratório. Dado este ponto de vista, nos propomos a passar da abordagem chamada "gestão dos fluxos migratórios” para uma chamada "governança da migração”, que visa a incluir os direitos e interesses dos migrantes no centro do debate. O que queremos mostrar neste artigo, é que a perspectiva hegemônica fez invisível as condições econômicas e demográficas dos países de destino que apóiam e dão espaço para a imigração, ea contribuição desses imigrantes para a dinâmica do economia e reprodução dessas sociedades. Queremos mostrar as estimativas da contribuição de imigrantes latino-americanos para a dinâmica econômica e social dos Estados Unidos e da Espanha, o principal destino deste fluxo migratório. Para fazer isso, nós fornecemos o sustento na análise de dados quantitativos e informações a partir de estatísticas oficiais de ambos os países e para o desenvolvimento de um modelo analítico que busca oferecer uma visão abrangente do papel da migração internacional na reprodução social demográfica e econômica nas sociedades avançadas.

Palavras-chave: migração e desenvolvimento, demografia, migração, América Latina, Estados Unidos, Espanha.

$* * *$

\section{Introducción}

Aunque suele plantearse que la relación Migración-Desarrollo es un fenómeno complejo y multifacético, al final de cuentas el debate ha estado hegemonizado por la visión que los países receptores y organismos internacionales tienen de ella. En particular, en la última década se ha consolidado el análisis de la migración internacional desde el enfoque de la seguridad nacional de los países receptores. No es casual que sea precisamente en estos años hayan tomado fuerza las posiciones políticas conservadoras que sustentan la criminalización de la migración indocumentada, y que impulsan diversas políticas de control inmigratorio, incluyendo la proliferación de muros que buscan frenar la migración, así como diversas políticas de deportación y retención de inmigrantes, pasando por la proliferación de centros de detención y retención de inmigrantes. 
Más allá de lo cuestionable que resulta este tipo de planteamientos, lo que nos interesa resaltar en esta oportunidad, es que esta perspectiva ha llevado a invisibilizar tanto las condiciones económicas y demográficas de los países de destino que sustentan y dan espacio a la inmigración, así como el aporte de estos inmigrantes a la dinámica de la economía y de la reproducción social en las sociedades de destino.

En efecto, en los países de destino suele hablarse más bien de una cuestión migratoria, esto es, en términos de los problemas sociales, económicos o políticos que plantea la inmigración masiva, máxime cuando se considera, además, la alta proporción de migrantes indocumentados y que se establecen en forma irregular (Ruhs y Martins, 2008). Por un lado, se plantean las tensiones sociales generadas por la inmigración masiva, así como por la ausencia de procesos de integración-asimilación de los migrantes en las sociedades de destino. Por otro lado, se enfatizan los costos económicos de la inmigración (en seguridad social, educación, salud, carga fiscal, entre otros) que el Estado debe asumir para mantener a esta población inmigrante (Smith y Edmonston, 1997). Por último, se señala que la migración (especialmente la indocumentada) tiene un impacto negativo sobre el mercado laboral ahondando los problemas sociales derivados del desempleo y bajos salarios (Martín, 2002; Borjas, 2001).

Frente a estos enfoques que se escudan en el discurso de la necesidad de una adecuada gestión y management de los flujos migratorios, surge con fuerza una visión que invierte los términos del debate y que sitúa la problemática de la migración desde otras perspectivas, poniendo especial énfasis en el enfoque de los derechos humanos y la responsabilidad de los Estados receptores en esta materia. No es casual que desde esta visión, se plantee la necesidad de pasar del enfoque del llamado management migration, que predomina en los gobiernos de los países centrales y diversas instituciones internacionales, a uno de la así llamada gobernanza de la migración, que busca incluir los derechos e intereses de los migrantes en el centro del debate de la migración y el desarrollo.

Considerando este enfoque alternativo y crítico, creemos que es necesario cambiar la perspectiva de análisis, de modo de poner en el centro del debate el papel de la migración contemporánea en la configuración y estructuración de las sociedades globales. Los inmigrantes no son ni los malos de la película, ni los salvadores y redentores del mundo contemporáneo. La migración, como proceso social, no es sino un engranaje más que hace funcionar las sociedades actuales, y ante lo cual, lo relevante es desentrañar las formas en que ello ocurre, entendiendo que las tensiones y conflictos que ello genere, son producto no de la migración en sí y por sí misma, sino de la sociedad en su conjunto. La migración como proceso social, pasa a ser así, una pieza más de este gran puzzle que representa a la sociedad global, y que le imprime determinados sellos y significados a la dinámica social en el mundo contemporáneo.

En este sentido, nuestro interés en este texto, es contribuir a esta perspectiva que busca visibilizar a los migrantes y la migración como un proceso social multifacético, generando y mostrando datos empíricos y análisis estadís- 
ticos que ilustren el aporte de los migrantes en diversos ámbitos y dimensiones sociales. En particular, en esta ocasión, nos interesa mostrar estimaciones sobre el aporte de los inmigrantes latinoamericanos a la dinámica económica y social de los Estados Unidos y España, principales destino de este flujo migratorio. Para ello, nos sustentaremos en el análisis de datos cuantitativos e información proveniente de estadísticas oficiales de ambos países. Este análisis empírico a su vez, se inscribe en un modelo de análisis que busca ofrecer una visión comprehensiva del papel de la migración internacional en la reproducción social, demográfica y económica en las sociedades avanzadas.

\section{La centralidad de la inmigración en las sociedades avanzadas}

Para entender el papel y significado de la migración en las sociedades avanzadas, es necesario considerar primeramente, las transformaciones y estructuración de estas sociedades en la época actual. Desde nuestra perspectiva, consideramos al menos tres ámbitos desde los cuales podemos analizar y comprender el papel de las migraciones en estas transformaciones de las sociedades de los países centrales, principales receptores de la inmigración proveniente del Tercer Mundo.

- Por un lado, las transformaciones demográficas, derivadas tanto del envejecimiento de la población nativa, como del advenimiento de la llamada segunda transición demográfica, misma que se expresa fundamentalmente en los cambios en la dinámica familiar y reproductiva de la población, y que se sustenta en los procesos de individuación propios de las sociedades postmodernas y globalizadas del mundo actual.

- Por otro lado, no podemos dejar de mencionar las transformaciones en la economía, y especialmente en el mundo del trabajo y del mercado laboral, derivadas de los procesos de globalización de la economía y la producción mundial.

- Por último, debemos también considerar las igualmente profundas transformaciones de la vida social y cultural, mismas que se expresan en el advenimiento de sociedades líquidas, así como la individuación de la vida social, procesos característicos del mundo postmoderno en las sociedades avanzadas.

Sobre cada uno de estos procesos se puede citar una amplia literatura que debate los alcances y formas que han adquirido así como de sus posibles variantes y consecuencias en los más diversos ámbitos. Lo que aquí nos interesa, es presentar un análisis que nos permita visibilizar cómo la inmigración contemporánea constituye un campo de articulación e integración de estos fenómenos, a la vez que contribuye a enfrentar diversos problemas y tensiones que genera la misma dinámica de estos procesos de las sociedades avanzadas. El siguiente diagrama nos permite ilustrar esta tesis sobre la centralidad que comienza asumir la migración internacional 
en la estructuración de las sociedades avanzadas.

En primer lugar, el cambio demográfico iniciado en las últimas décadas, se manifiesta crecientemente en un déficit persistente de mano de obra local. El envejecimiento de la población junto al descenso de la fecundidad en el marco de la segunda transición demográfica (STD), conllevan no sólo un lento y a veces nulo crecimiento demográfico, sino por sobre todo, un cambio sustancial en la estructura etárea de la misma, incrementándose la población en edades adultas, y reduciéndose la de edades jóvenes. Este cambio demográfico ya está afectando directamente la capacidad de las sociedades avanzadas, para proveerse internamente de la población activa necesaria para mantener los ritmos de crecimiento económico y transformación productiva. Se trata además de economías que necesitan generar los excedentes necesarios para mantener no sólo sus altos niveles de vida y patrones de consumo suntuosos, sino por sobre todo, necesitan mantener y reproducir cotidianamente una amplia clase ociosa (en términos de Veblen), especialmente en términos de una industria de guerra y de un ejército de administración de la economía y la política internacional, que les permita mantener su privilegiada posición dominante y hegemónica en la sociedad mundial.

Digámoslo en términos más simples. La demografía en estas sociedades, presenta una evidente insuficiencia estructural para generar los contingentes de trabajadores que ocupen los puestos de trabajo que la dinámica y crecimiento económico de estas mismas sociedades genera cotidianamente. Frente a este desajuste estructural entre la dinámica demográfica interna y la dinámica económica, la solución ha sido apelar a la inmigración masiva de trabajadores, provenientes en su mayoría de países del Tercer Mundo, donde se vive un régimen demográfico diferente.

\section{Figura 1 \\ Modelo de análisis y entendimiento de la migración internacional en las sociedades avanzadas}

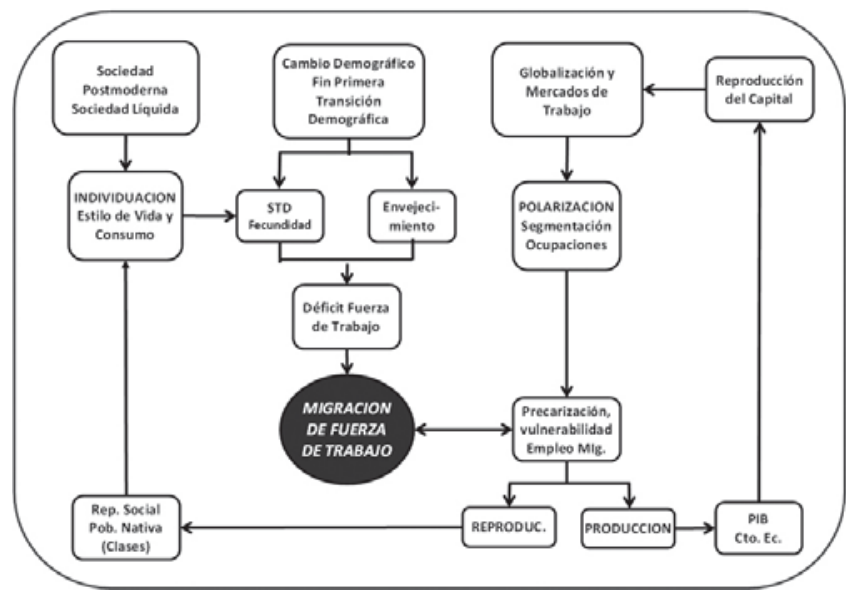


Paralelamente a estos cambios demográficos, las economías desarrolladas están experimentando una serie de transformaciones económicas y productivas, en el marco de la globalización. Para nuestra discusión, lo más relevante de estos procesos, se refieren a las transformaciones en la dinámica de los mercados de trabajo en estas sociedades. En particular, queremos llamar la atención en la creciente polarización de la estructura de las ocupaciones, que indica que junto al auge de empleos y puestos de trabajo insertos directamente en la economía de la información, surgen y se expanden diversas actividades y ocupaciones de bajo nivel productivo, altamente precarias y vulnerables, pero que crecen a la par de las primeras. Nos referimos especialmente a trabajos como el servicio doméstico, industria del cuidado, mantenimiento y limpieza, preparación de alimentos, entre muchos otros, todos ellos vinculados directamente a la reproducción social y cotidiana de la población de ingresos medios y altos de las sociedades avanzadas.

En este contexto de polarización e las ocupaciones, derivado de la misma globalización económica, en las sociedades avanzadas se estarían configurando diversos nichos de mercados en los cuales suelen insertarse preferentemente los trabajadores inmigrantes, quienes por su misma condición migratoria y muchas veces indocumentada, no tienen las herramientas sociales y políticas necesarias para enfrentar y renegociar las condiciones de precariedad, vulnerabilidad e inestabilidad laboral que prevalece en estos segmentos del mercado laboral.

Finalmente, cabe señalar que esta polarización y auge de las ocupaciones vinculadas a los servicios reproductivos y personales, no está ajena de las transformaciones sociales y culturales que desde hace algunas décadas experimentan las sociedades avanzadas, ene 1 marco de lo que Bauman ha denominado como postmodernidad o sociedades líquidas. Por un lado, el mismo desarrollo económico promueve nuevos patrones de consumo y estilo de vida, favoreciendo la mercantilización de muchas actividades vinculadas a la reproducción social y cotidiana, que antes se realizaban en los espacios de la vida privada y familiar. Los procesos de individuación y cambios en el papel del hogar y la familia, por ejemplo, junto a la creciente incorporación de la mujer a la vida pública y laboral, conllevan una cierta liberación y emancipación de las antiguas cadenas que las ataban a las tareas del hogar.

Estos cambios sociales, también abren un espacio para la creciente incorporación de trabajadores inmigrantes, hombres y mujeres, en estas diversas actividades vinculadas a la reproducción social de la población nativa. Desde esta perspectiva, la migración internacional también contribuye a sustentar los cambios sociales, culturales y demográficos que caracterizan a las sociedades avanzadas contemporáneas. Así por ejemplo, tanto el cuidado de niños y ancianos, como el mismo servicio doméstico deja de ser una tarea propia de las mujeres nativas, para convertirse en un trabajo mercantilizado que realizan las inmigrantes, pero bajo las condiciones que dicta la flexibilidad laboral y la desregulación contractual de las sociedades postindustriales. 
Considerando lo anterior, a continuación presentamos un análisis que busca ilustrar con datos empíricos y argumentos conceptuales, este modelo de entendimiento de la centralidad de la migración en las sociedades avanzadas. Tomamos como puntos de referencia la migración latinoamericana a España y los Estados Unidos. Asimismo, siguiendo la exposición del modelo general, partimos con el análisis del papel de la migración frente a los cambios demográficos en estas sociedades, para después continuar con su papel económico en la reproducción del capital, y su participación en la reproducción social de las clases medias y altas de ambos países.

\section{La migración internacional frente al cambio demográfico en las sociedades avanzadas}

El aporte de la inmigración al mercado laboral, ha sido ampliamente analizado y discutido en la literatura (Pioré, 1979; Sassen, 2007). En esta ocasión, quisiéramos centrarnos en un aspecto que aunque no muy mencionado, a nuestro entender resulta cada vez más relevante para entender y dimensionar el aporte de la inmigración contemporánea en los países de destino. Nos referimos al cambio demográfico que se vive en las sociedades avanzadas, y que se manifiesta en la dinámica de dos fenómenos diferentes pero complementarios: el envejecimiento de la población y el advenimiento de la Segunda Transición Demográfica.

La segunda Transición demográfica. Se trata de un modelo propuesto por van de Kaa (1987), para explicar la dinámica demográfica en las sociedades europeas de fines del siglo XX, y que experimentaran un continuo descenso en los niveles de fecundidad, llegando en algunos casos a estar incluso por debajo de los niveles que asegurarían la reproducción demográfica. De acuerdo a este autor, estos cambios en el comportamiento demográfico y reproductivo, radican en el proceso de individuación que prevalece actualmente en las sociedades avanzadas, mismos que permiten definirlas como sociedades líquidas, postmaterialistas y postmodernas (Bauman, 2003). En las sociedades avanzadas los valores familiares propios del capitalismo industrial (trascendencia a través de la descendencia, los hijos y la familia, por ejemplo), tienden a ser desplazados por los valores de autorrealización personal, de libertad y autonomía individual (van de Kaa, 2002) ${ }^{1}$.

Las consecuencias demográficas de este fenómeno, son de dos tipos. Por un lado, implica un cambio en la composición y dinámica de los hogares y familias, y por otro, un continuo descenso en los niveles de fecundidad. En el primer caso, el tradicional modelo de familia nuclear, ha quedado desfasado, imponiéndose una variedad y diversidad de patrones de uniones y de familias, las cuales además, presentan una evolución y cambio de gran dinamismo. Frente al descenso de las familias nucleares tradicionales, se antepone el incremento de las personas que viven solas, así como de familias monoparentales, familias recompuestas, y de hogares 
compuestos. Asimismo, ha aumentado la tasa de divorcio, la de cohabitación, y se ha reducido la tasa de nupcialidad (Herrera, 2007).

Por otro lado, el descenso de la fecundidad se debe ya no tanto al impacto del uso de métodos modernos de anticoncepción (los cuales ya son de uso generalizado por la población), como a factores sociales que han modificado el comportamiento y actitud frente a los hijos y la descendencia, y que se manifiestan en un mayor retardo en la edad al primer hijo, pero sobre todo, al aumento de madres con un solo hijo, y al incremento de parejas y de mujeres que no desean tener hijos (Bongaarts, 2001).

$\mathrm{Al}$ respecto, los datos para Estados Unidos y España resultan claramente ilustradores. Por un lado, en ambos países se pasa de una tasa global de fecundidad superior a los 2.5 hijos por mujer en 1970, a niveles por debajo del nivel de remplazo. Sin duda, este descenso es más marcado en el caso de España, en donde la TGF ha llegado a niveles inferiores al 1.5 hijos por mujer, mientras que en Estados Unidos, aunque el descenso es igualmente sistemático, es sin embargo menos pronunciado, alcanzándose actualmente una TGF de 1.8 hijos por mujer. Asimismo, en el caso de España resulta ilustrativo que el descenso de la fecundidad se estabiliza en los noventa para recuperarse levemente en los años 2000. Ello puede explicarse por la conjunción de dos factores. Por un lado, la bonanza económica que experimentó España a partir de la década de los noventa, y por otro lado, el incremento de la inmigración, especialmente de mujeres provenientes de América Latina, las cuales presentan históricamente mayores niveles de fecundidad que las mujeres españolas.

Figura 2

Estados Unidos y España. Tasa Global de Fecundidad, 1970-2010

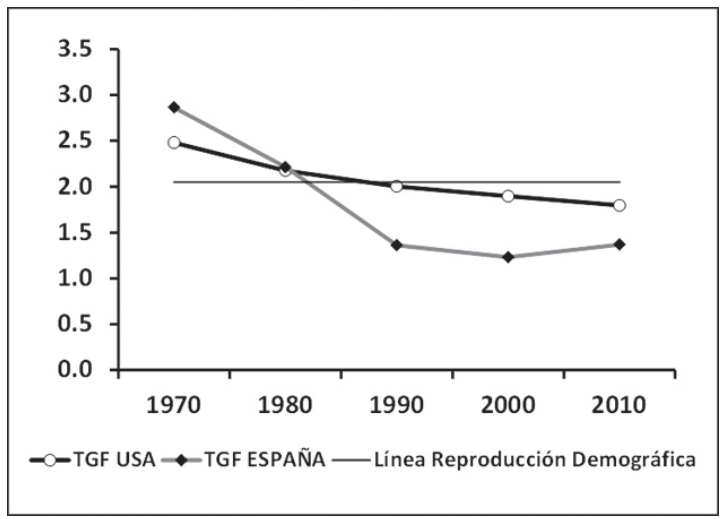

Fuentes: Estados Unidos, CDC Vital Statistics Data Available Online, http:// www.cdc.gov/nchs/data_access/Vitalstatsonline.htm y España, INE. Indicadores demográficos básicos. Natalidad y Mortalidad. www.ine.es 
Por otro lado, cabe señalar que la segunda transición demográfica no sólo se expresa en este descenso de la fecundidad general, sino también y particularmente, en el comportamiento reproductivo por edades de la madre. Al respecto, los datos para ambos países, son igualmente elocuentes. Hacia 1970, en ambos casos prevalecía un patrón de fecundidad temprana, esto es, donde la mayor tasa de nacimientos se daba entre las mujeres jóvenes, de 20 a 24 años. No obstante, actualmente la mayor tasa de fecundidad se da entre las mujeres de 30 a 34 años, en el caso de España, y de 25 a 34 años en el caso de los Estados Unidos. Este retraso en la fecundidad es reflejo de los procesos de individuación, que en el caso de las mujeres ha implicado un cambio radical, especialmente en términos de la mayor importancia que adquiere el estudio, el trabajo, y la realización personal, por sobre los tradicionales valores de la maternidad. Esto explicaría este doble proceso, de por un lado, reducir el número de hijos, a la vez que retardar su nacimiento, desde etapas tempranas de su ciclo de vida, a etapas intermedias, adelantando en cambio, la culminación de los estudios, su inserción al mercado laboral, y otros comportamientos que fortalecen su participación e inserción en la sociedad como individuos independientes.

\section{Figura 3}

Estados Unidos y España. 1970-2012. Tasas específicas de fecundidad por edad de la madre

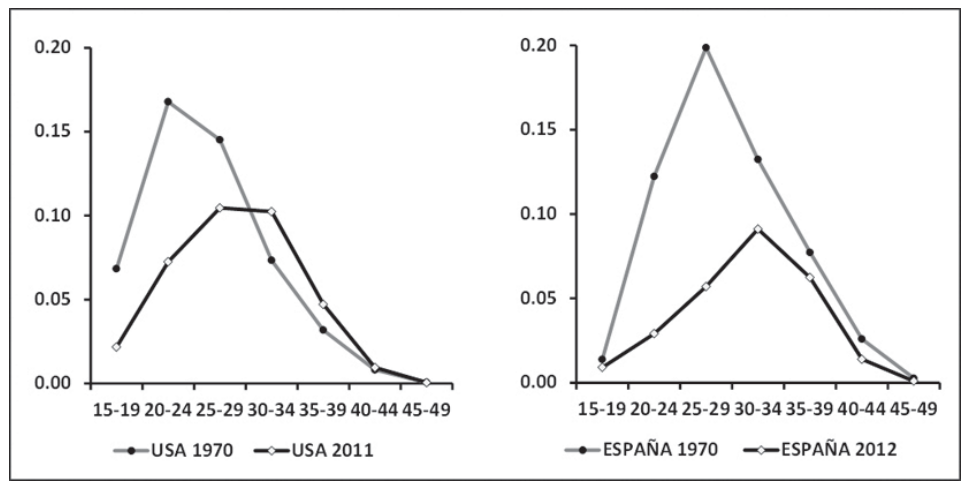

Fuentes: Estados Unidos, CDC Vital Statistics Data Available Online, http:// www.cdc.gov/nchs/data_access/Vitalstatsonline.htm y España, INE. Indicadores demográficos básicos. Natalidad y Mortalidad. www.ine.es

El envejecimiento demográfico. El proceso de envejecimiento se refiere al cambio en la composición y estructura etárea de la población, como resultado de los cambios en la dinámica de la mortalidad y de la fecundidad, que se consolidaron bajo el contexto de la primera transición demográfica. Se llama envejecimiento, pues la tradicional estructura por edades de la población, que adoptaba una forma piramidal, con una base 
amplia producto de las altas tasas de fecundidad y natalidad, y una cúspide baja y angosta, producto de los altos niveles de mortalidad, comienza a adquirir una forma más bien de una ojiva, con una base en continuo estrechamiento, derivado de la reducción de los nacimientos, y una cúspide que a la vez que se eleva, también se ensancha, producto de la reducción de la mortalidad, y el incremento en la esperanza de vida de las personas.

En los países desarrollados, principal destino de las migraciones internacionales actuales, este proceso de envejecimiento se encuentra más avanzado, y ya se expresa en un cambio en la estructura etárea de su población.

En el caso de España, por ejemplo, la proporción que representa la población de 65 años y más, ha empezado a crecer sistemáticamente desde los años setenta, pasando de representar menos del 10\% de la población total en 1970, a casi el 17\% en el 2010. Asimismo, la población infantil (menores de 15 años), muestra la tendencia inversa, pasando de casi el 28\% en 1970, a sólo el 15\% en el 2010. En los Estados Unidos, sucede algo similar. Mientras los adultos mayores incrementan su participación, desde el 8\% en los años cincuenta, al 15\% en el 2010, a población infantil repite el comportamiento que se da en España, pasando de casi el 30\% en los cincuenta, a cerca del 17\% en el 2010.

La conjunción de ambas tendencias, tienen prácticamente el mismo efecto en ambos países, y se expresan en el sistemático crecimiento del índice de envejecimiento de su población. En el caso de Estados Unidos, por ejemplo, se pasa de una relación de más de 3 niños menores de 15 años, por cada adulto de 65 años o más, en 1950, a una relación casi paritaria entre ambos grupos etáreos en la actualidad. En el caso de España, este cambio es aún más intenso, pues en menos tiempo, no solo se reduce esta relación, sino que incluso se ha invertido. Si en 1970 la población infantil superaba a la adulta mayor en una relación de casi 3 a 1, en la actualidad es la población adulta mayor la que supera a la infantil en algo más de un $15 \%$, tendencia que se espera continúe incrementándose en las siguientes décadas.

\section{Figura 4}

\section{Estados Unidos y España, 1950.2010. Población infantil y adulta mayor (\%) e Indice de envejecimiento demográfico}

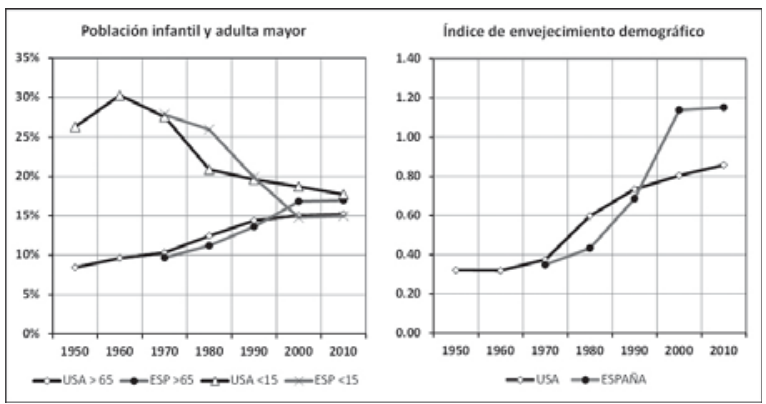

Fuentes: España: INE, Evolución de la población de España entre los Censos de 1970 y 1981, Estimaciones intercensales de población, 1991-2010. Estados Unidos: Hobbs, Frank y Nicole Stoops. 2002; y Current Population Survey, March Supplement. 2010. 
Migración y cambio demográfico: el déficit de Fuerza de Trabajo. Estas tendencias derivadas tanto de la segunda transición demográfica, como del envejecimiento de la población, configuran una situación de inestabilidad demográfica, que tiene serios impactos en la dinámica y estabilidad económica y social en estas sociedades. En concreto, el sistemático descenso de la fecundidad y natalidad, junto al envejecimiento demográfico, se manifiestan en un persistente déficit de población en edades activas y de la fuerza de trabajo necesaria para sustentar la dinámica y crecimiento de la economía de los países desarrollados, comprometiendo así, la capacidad de reproducción económica de la población de estos países, así como de sus estilos de vida y patrones de consumo y reproducción social (Canales, 2011; Cooke, 2003).

En efecto, y aún a pesar de los efectos negativos de la crisis económica en la generación y crecimiento del empleo, ya en la última década constatamos un persistente y creciente desequilibrio entre la oferta de puestos de trabajo que genera el crecimiento económico, y que demanda por tanto, la reproducción del capital, y la oferta de mano de obra que la demografía local está en condiciones de generar.

En el caso de España, por ejemplo, entre 1999 y el 2012, la economía logró generar 3.8 millones de nuevos empleos, ello a pesar del serio impacto de la crisis de los últimos años. Sin embargo, la dinámica demográfica de la población española (sin los inmigrantes), logró generar tan sólo 1.7 millones de nuevos trabajadores, generándose así un déficit de mano de obra que alcanza los 2.1 millones de personas. Esto es, la economía española, aún en un contexto de lento crecimiento derivado de la crisis económica actual, genera una oferta de empleo, que es más de un 125\% superior a la capacidad de crecimiento demográfico de su población activa.

\section{Figura 5}

\section{España y Estados Unidos. Estimación del déficit de mano de obra, crecimiento del empleo y de la población económicamente activa}

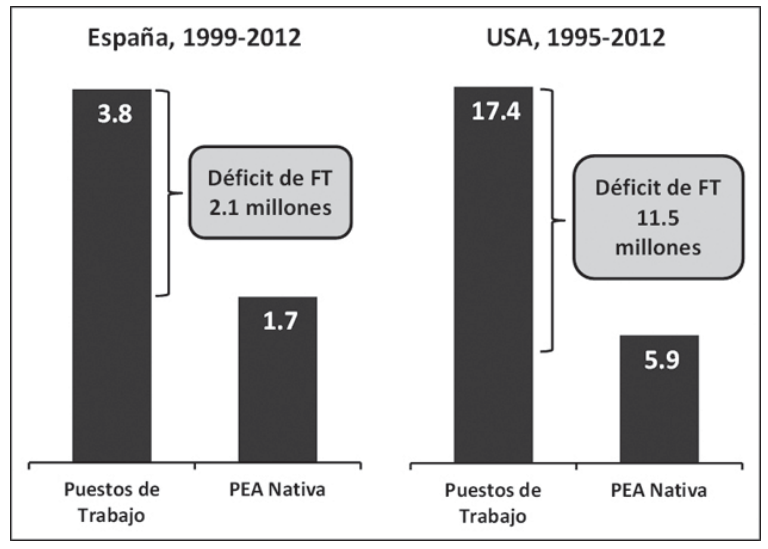

Fuentes: Estimaciones propias, con base en España: INE, Encuesta de Población Activa, 1999 y 2012; y Estados Unidos: Current Population Survey, March Su-plemment, 1995 y 2012. 
Por su parte, en el caso de los Estados Unidos, la situación es muy similar. Entre 1995 y el 2012, la dinámica de crecimiento de su economía logró generar 17.4 millones de nuevos empleos, sin embargo, la dinámica demográfica de su población nativa, apenas pudo generar una oferta de fuerza de trabajo de 5.9 millones de personas. En este caso, el déficit de mano de obra supera en casi un $200 \%$ la capacidad demográfica de su población nativa.

Considerando lo anterior, nuestra tesis es que en los países avanzados, la inmigración desde países periféricos contribuye a llenar el vacío demográfico que se genera por la insuficiencia estructural de sus actuales patrones de reproducción demográfica, y que se manifiesta en toda su magnitud en el persistente déficit de población económicamente activa que hemos mostrado previamente, y que presiona a estas sociedades a recurrir a mano de obra migrante para cubrir las ocupaciones que la dinámica económica está generando cada año. En este marco, podemos comprender no sólo la dinámica y volumen de la inmigración laboral a estos países, sino también su papel para contrarrestar los efectos que el envejecimiento de la población nativa tendría sobre su dinámica económica.

$\mathrm{Al}$ respecto, un primer aspecto que evidencia el aporte de la inmigración latinoamericana a la fuerza de trabajo en los países centrales, es su volumen actual, así como su crecimiento en las últimas décadas. En el caso de los Estados Unidos, por ejemplo, en 1995 había 6.8 millones de inmigrantes latinoamericanos en la fuerza de trabajo de los Estados Unidos, los que representaban apenas el 5\% del total de la fuerza de trabajo. A partir de entonces, este volumen se incrementa sistemáticamente, hasta alcanzar los 13.3 millones en el 2012, los que representan el 8.6\% de la fuerza de trabajo de los Estados Unidos.

\section{Figura 6 \\ Estados Unidos y España. Inmigrantes Laborales provenientes de América Latina (millones de personas)}

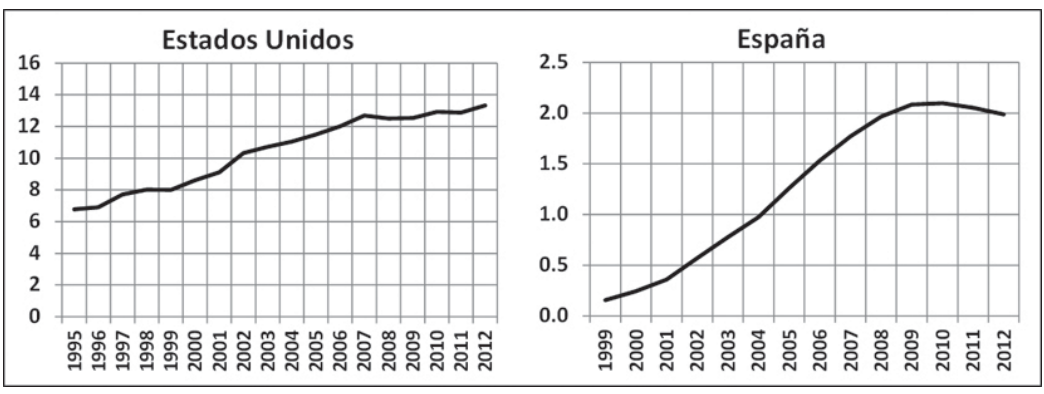

Fuentes: Estimaciones propias, con base en España: INE, Encuesta de Población Activa, 1999 a 2012; y Estados Unidos: Current Population Survey, March Suplemment, 1995 a 2012. 
En el caso de España, sucede algo similar. Hacia 1999, la inmigración latinoamericana era prácticamente marginal. Se registraba tan solo 158 mil trabajadores latinoamericanos trabajando ene se país, los que representaban menos del 1\% de la fuerza de trabajo. Para el 2012, en cambio, la inmigración latinoamericana ya aportaba el $8.6 \%$ de la fuerza de trabajo, e involucraba a un volumen de casi 2 millones de trabajadores.

Si bien en los últimos años se da un leve descenso del volumen de trabajadores latinoamericanos en España, así como un estancamiento en los Estados Unidos, en ambos casos se debe principalmente a los efectos de la crisis económica, la cual sin embargo, no ha tenido los efectos que se vaticinaban en términos de generar un retorno masivo de inmigrantes a sus países de origen.

\section{Figura 7 \\ Inmigrantes laborales de Latinoamérica, como \% de la Fuerza de Trabajo local}

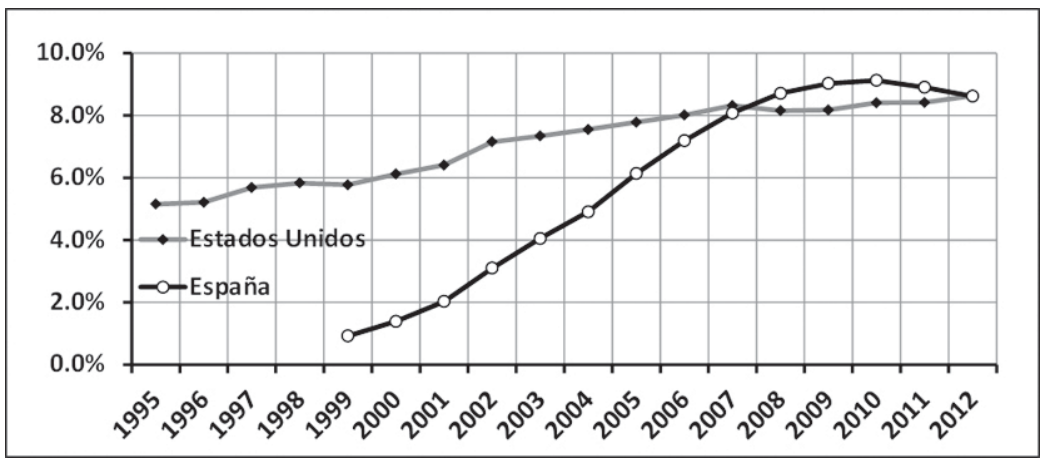

Fuentes: Estimaciones propias, con base en España: INE, Encuesta de Población Activa, 1999 a 2012; y Estados Unidos: Current Population Survey, March Suplemment, 1995 a 2012.

Ahora bien, esta tendencia de la migración de origen latinoamericano en ambos países, ha contribuido a saldar en parte el déficit de mano de obra que ya hemos señalado para ambos países. En efecto, en el caso de España, por ejemplo, entre el 2000 y el 2012, la inmigración latinoamericana ha contribuido a cubrir un tercio del crecimiento de la fuerza de trabajo en ese país, ello a pesar de los efectos negativos de la crisis económica, especialmente en cuanto a la reducción de los puestos de trabajo y caída del empleo en diversos sectores económicos, donde se insertan preferentemente los inmigrantes (construcción, por ejemplo). En el caso de los Estados Unidos, sucede algo similar, registrándose que la inmigración latinoamericana habría aportado el 35\% del crecimiento de la fuerza de trabajo en esos mismos años. 


\section{Figura 8}

\section{Estados Unidos y España. 2000-2012. Composición del crecimiento de la Fuerza de Trabajo según origen migratorio.}
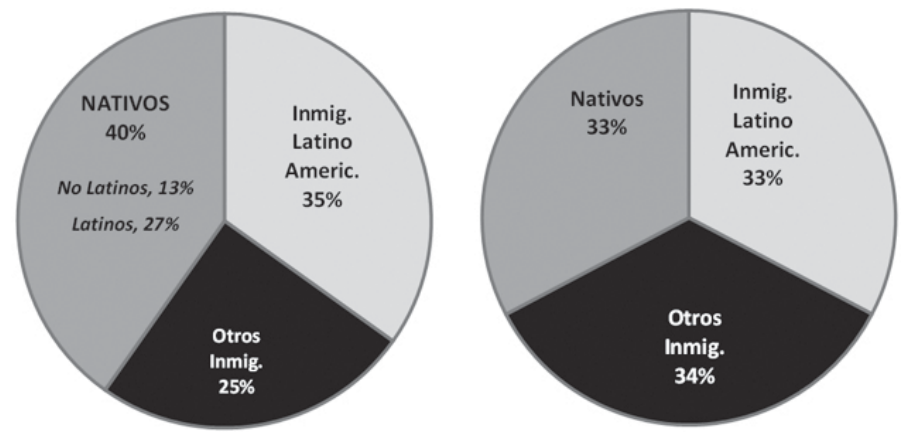

Fuentes: Estimaciones propias, con base en España: INE, Encuesta de Población Activa, 2000 y 2012; y Estados Unidos: Current Population Survey, March Suplemment, 2000 y 2012.

En diversos textos se señala que esta inmigración laboral constituiría una presión innecesaria sobre el mercado de trabajo, provocando un virtual desplazamiento de mano de obra nativa de sus puestos de trabajo (Borjas, 2001; Martin, 2002). En realidad, la situación es mucho más compleja. Como veremos a continuación, los datos indican que más que un supuesto desplazamiento del mercado de trabajo de un grupo étnico (trabajadores nativos) por otro (inmigrantes), lo que está sucediendo es el virtual agotamiento del crecimiento demográfico de un grupo étnico (nativos), producto del proceso de envejecimiento y descenso de la natalidad que están actualmente experimentando.

En efecto, como se ilustra en la siguiente gráfica, es evidente el efecto que el envejecimiento demográfico está teniendo sobre la estructura etárea de la población económicamente activa nativa. En el caso de los Estados Unidos, por ejemplo, es evidente el envejecimiento de la fuerza de trabajo nativa no latina. En tan sólo 12 años (del 2000 al 2012) se ha reducido en casi 12 millones de personas la fuerza de trabajo menor de 50 años, a la vez que se ha incrementado en casi 14 millones la mayor a esa edad. En el caso de España, sucede algo similar, aunque en menor intensidad. Por un lado, entre los mismos años, la fuerza de trabajo nativa menor de 50 años se redujo en algo más de 110 mil personas, a la vez que la de mayor de esa edad se ha incrementado en 1.8 millones de personas. 


\section{Figura 9}

\section{Estados Unidos y España. 2000-2012. Crecimiento de la Fuerza de Trabajo, según grandes grupos de edad y origen migratorio (millones de personas)}

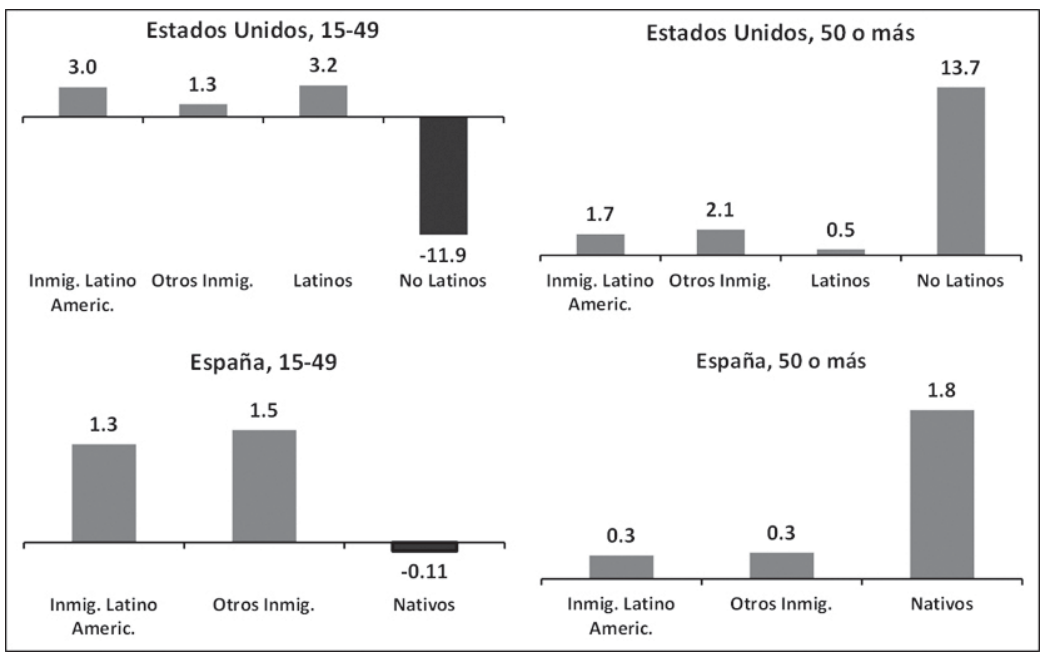

Fuentes: Estimaciones propias, con base en España: INE, Encuesta de Población Activa, 2000 y 2012; y Estados Unidos: Current Population Survey, March Suplemment, 2000 y 2012.

En otras palabras, en ambos países, el envejecimiento de la población nativa que ya hemos documentado, es de tal magnitud, que su dinámica demográfica ya no le permite reponer su fuerza de trabajo, la cual también presenta un claro proceso de envejecimiento en términos absolutos.

Ahora bien, el vacío que el envejecimiento de la población nativa está dejando en las edades jóvenes de la población económicamente activa (menores de 50 años), está siendo compensado por la dinámica de crecimiento de la población de origen migrante, tanto proveniente de Latinoamérica, como de otras regiones del Tercer Mundo.

En el caso de los Estados Unidos, la fuerza de trabajo inmigrante menor de 50 años, se incrementó en 4.3 millones de personas, de las cuales, 3 millones corresponden a inmigrantes latinoamericanos, y 1.3 a otras regiones del mundo. Si a ello sumamos el crecimiento de los descendientes de inmigrantes latinoamericanos, quienes crecieron en otros 3.2 millones de trabajadores, vemos que en conjunto, estas minorías demográfica, contribuyen a paliar en gran medida el efecto negati- 
vo que genera el descenso absoluto de la población ocupada de origen nativo en estas edades.

En el caso de España, sucede algo similar. Aquí, también el crecimiento de la fuerza de trabajo menor de 50 años, se sustenta exclusivamente en el aporte que hacen los trabajadores inmigrantes, los que crecieron en 2.8 millones de personas activas, de las cuales, 1.3 millones provenían de Latinoamérica, y 1.5 millones de otros países del mundo.

En síntesis, estos datos indican que más que un proceso de desplazamiento de fuerza de trabajo nativa por fuerza de trabajo inmigrante, lo que está ocurriendo tanto en España como en los Estados Unidos, es un virtual remplazo demográfico de un grupo étnico por otro, producto en gran medida, de la propia insuficiencia de crecimiento demográfico de la población nativa.

Ahora bien, el aporte de la inmigración no se refleja sólo en paliar el déficit de mano de obra que la demografía de las sociedades avanzadas está generando, sino que a través de este aporte a la composición de la fuerza de trabajo, contribuye además a mantener la dinámica y crecimiento de la economía de estas sociedades. Al respecto, los datos también resultan ilustrativos, en términos de mostrar cómo la inmigración contribuye cada vez más a la generación del PIB y acumulación de capital en las sociedades avanzadas. Esta tesis la podemos ilustrar con estimaciones que hemos desarrollado sobre la contribución de la inmigración latinoamericana al crecimiento del PIB en España y los Estados Unidos.

Con base en un modelo que estima las productividades medias según sectores de actividad, hemos calculado el volumen del PIB que es generado por la fuerza de trabajo según su condición étnica y migratoria, tanto en el caso español, como en el de los Estados Unidos ${ }^{2}$. Con base en este modelo, hemos estimado el volumen del PIB que cada año genera tanto la población trabajadora nativa como la inmigrante, y con ello, estimamos el aporte de cada uno de ellos al crecimiento del PIB en cada país.

$\mathrm{Al}$ respecto, los datos son muy ilustrativos. En el caso de España, por ejemplo, entre el 2000 y el 2011, sólo el 33\% del crecimiento económico es aportado por la fuerza de trabajo nativa (españoles), mientras que el $67 \%$ restante ha sido generado por los trabajadores inmigrantes. Destaca el caso de los de origen latinoamericano, quienes en conjunto aportaron del 35\% del crecimiento económico en esos años. 


\section{Figura 10}

Estados Unidos y España. Composición del crecimiento del Producto Interno Bruto, según origen migratorio de la fuerza de trabajo

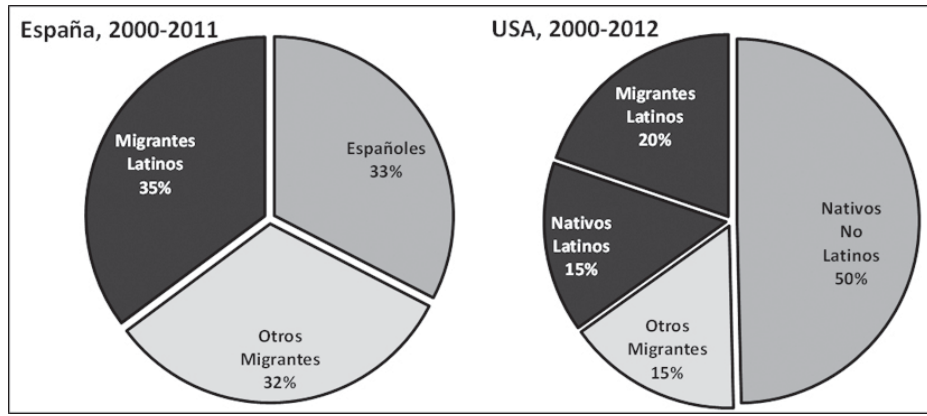

Fuentes: España, INE, Contabilidad Nacional de España, PIB por rama de actividad, y Encuesta de Población Activa, 2000 y 2011 www.ine.es Estados Unidos, Buró de Análisis

Económico, Real Value Added by Industry, http://www.bea.gov/industry/index.htm y

Buró del Censo, Current Population Survey, March Suplemment, 2000 y 2012.

En el caso de los Estados Unidos, sucede algo similar. Aquí, si bien la fuerza de trabajo nativa no latina aporta el 50\% del crecimiento del PIB, ello no demerita el gran aporte de los inmigrantes latinoamericanos, quienes aportan un quinto del crecimiento económico de la última década en ese país. Si a ello agregamos el aporte de sus descendientes, vemos que los latinos se constituyen en la minoría demográfica con mayor peso e importancia en cuanto a su contribución al crecimiento económico, y por ese medio, a mantener el poderío económico y político de esa nación a nivel mundial.

Este aporte al crecimiento económico, puede entenderse también como una estimación del nivel de dependencia de las economías de las sociedades avanzadas respecto a la necesaria provisión de mano de obra inmigrante, ante la insuficiencia demográfica que ya se manifiesta en su población nativa. Al respecto, esta dependencia de la inmigración, se ilustra aún más claramente cuando vemos el distinto comportamiento del PIB generado por cada grupo étnico-migratorio en estos años de crisis económica.

En el caso de España, mientras el PIB generado por la población nativa cayó entre el 2008 y el 2011 a una tasa del $1.7 \%$ en promedio cada año, el PIB generado por los migrantes latinos se redujo en un $0.8 \%$ anual cada año. Asimismo, en el caso de los Estados Unidos, donde la crisis ha golpeado menos intensamente, los datos son aún más claros. Entre el 20008 y el 2012, el PIB generado por los trabajadores nativos no latinos apenas se incrementó en un $0.1 \%$ cada año. Por el contrario, el PIB generado por los 
inmigrantes latinos, y por sus descendientes se incrementó a una tasa del 2.6\% y 3.7 cada año, respectivamente.

\section{Figura 11 \\ Estados Unidos y España. Tasa de crecimiento del Producto Interno Bruto, según origen migratorio de la fuerza de trabajo}

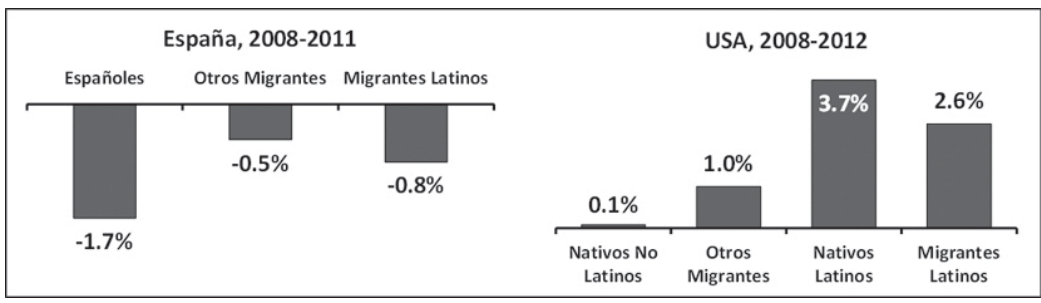

Fuentes: España, INE, Contabilidad Nacional de España, PIB por rama de actividad, y Encuesta de Población Activa, 2008 y 2011 www.ine.es Estados Unidos, Buró de Análisis

Económico, Real Value Added by Industry, http://www.bea.gov/industry/index.htm y

Buró del Censo, Current Population Survey, March Suplemment, 2008 y 2012.

Estos datos ilustran el nivel de importancia que adquiere la inmigración laboral para sostener el crecimiento económico, y por tanto, para la reproducción ampliada del capital, en los países desarrollados, especialmente en estos años de crisis económica. Tenemos claro que la migración no es el único factor, pero también no queda duda que no deja de tener un papel relevante.

\section{Migración, globalización y mercados de trabajo}

Este aporte de la migración laboral al crecimiento económico se enmarca además, en los cambios en la dinámica laboral y económica derivada de la globalización de la economía de las sociedades avanzadas. No es el momento de revisar y discutir este proceso, sólo nos interesa retomar los cambios en la dinámica del mercado laboral y estructura de ocupaciones que se derivan de él, y que configuran marco estructural de la inserción laboral de los migrantes.

$\mathrm{Al}$ respecto, diversos autores señalan que en términos de la organización del trabajo, la globalización ha implicado el pasar del ya clásico modelo industrial de producción en masa de tipo fordista, a uno de producción flexible, just in time, basado en los principios de organización industrial postfordistas (Lipietz, 1997). Si en el primero, se articulaba una base productiva nacional con una comercialización mundial, en el segundo, la globalización ha alcanzado también al mismo proceso de trabajo (Hobsbawm, 2000) Asimismo, si el primero daba origen a un orden social 
y estatal, identificado con el keynesianismo y el Estado de Bienestar como marcos de regulación de la economía, el segundo da origen a un nuevo orden económico y social mundial, sustentado en el neoliberalismo y el mercado como mecanismo de (des)regulación del funcionamiento de la economía (de la Garza, 1998).

Este contexto de producción flexible y la desregulación de los mercados, plantea no pocos cambios en la estructura y dinámica económica de las sociedades actuales. Entre ellos, destacan por su importancia, los cambios que afectan la estructura del empleo y las ocupaciones, y en general, las relaciones capital-trabajo, y que son la base del surgimiento de una nueva estructura de clases y estratificación social. Se trata en particular de la configuración de un nuevo patrón de polarización y diferenciación social, basado en dos procesos diferentes y complementarios.

- Por un lado, la reestructuración del régimen laboral con base en las nuevas estructuras de flexibilidad y desregulación laboral, que derivan en lo que Beck (2000) ha llamado como un régimen de riesgo laboral, que sustituye al régimen laboral e instituciones sociales surgidas a través del estado de Bienestar.

- Por otro lado, la transformación del sistema de ocupaciones con base en la creciente segmentación de ellas y la diferenciación y desigualdad social y laboral que ellas implican (Sassen, 2007, Pioré, 1979). El advenimiento de una economía de la información, conlleva la polarización de la estructura ocupacional en las sociedades informacionales, con el consecuente incremento de las ocupaciones y actividades ubicadas en los extremos de la estratificación socioocupacional (Castells, 1998).

En este régimen de riesgo laboral, los puestos y ocupaciones en auge no son sólo los más "ricos” en información o conocimiento incorporado, sino también hay un sostenido incremento de las ocupaciones en servicios y trabajos de baja calificación. Se trata del auge cuantitativo de empleos "no-informacionales", pero que al igual que su contraparte, forman parte de la nueva estructura social que caracteriza a la sociedad informacional (Bauman, 2011; Kumar, 1995).

No se trata ni de ocupaciones residuales ni de remanentes de sociedades pre-informacionales. Tampoco corresponden a empleos marginados, "excluidos" de los circuitos de producción y reproducción de la sociedad informacional. Por el contrario, corresponden a empleos y ocupaciones que surgen con la misma modernidad informacional, pero que están expuestos a formas extremas de flexibilidad salarial y desregulación contractual, lo que ha implicado su desvalorización social y económica. Corresponden a ocupaciones que constituyen piezas importantes en el proceso de reproducción de la sociedad informacional.

En términos cuantitativos, esta polarización se manifiesta en un cam- 
bio importante en el peso relativo de cada actividad y ocupación. Al respecto, los datos para Estados Unidos, permiten ilustrar esta tesis. Entre el 2000 y el 2012, el crecimiento económico acumulado en esos años, no arrastró tras de sí a todos los estratos ocupacionales por igual. De hecho, este ciclo está asociado a un cambio en la estructura ocupacional. Mientras las ocupaciones directamente productivas (manufactura, y similares) perdieron 6.4 millones de empleos, en los niveles más altos de dirección (ejecutivos, profesionales, etc.) así como en los niveles ocupacionales más bajos (tareas de la reproducción social), se generaron 8.6 y 5.6 millones de nuevos puestos de trabajo, respectivamente.

Figura 12

\section{Estados Unidos y España, 2000-2012. Crecimiento del empleo según tipo de ocupación (miles de puestos de trabajo ocupados)}

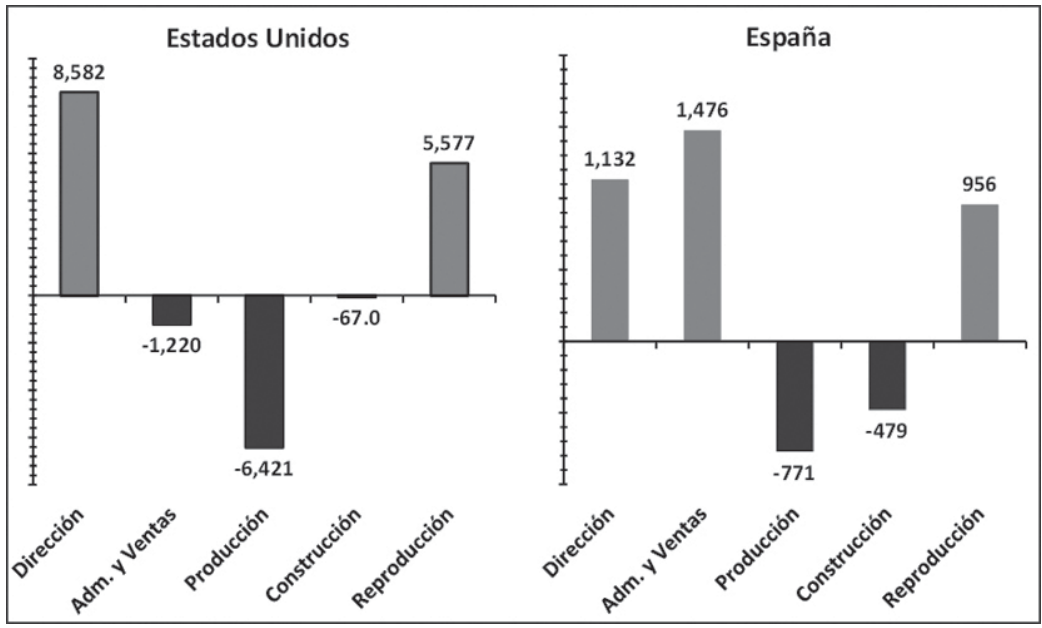

Fuentes: España, INE, Encuesta de Población Activa, 2000 y 2012 www.ine.es Estados Unidos, Buró del Censo, Current Population Survey, March Suplemment, 2000 y 2012.

En el caso de España, se da una tendencia similar, aunque con algunos matices. Por un lado, se observa también la caída del empleo en ocupaciones directamente productivas, la cual en igual periodo, implicó la pérdida de 770 mil empleos, a los que se les agregan otros 480 mil del sector de la construcción. Por otro lado, se constata el crecimiento del empleo en los extremos de la estructura ocupacional. Las ocupaciones de los niveles altos de dirección y puestos de servicios profesionales se incrementaron en 1.3 millones. Asimismo, el empleo en los niveles ocupacionales más bajos (servicio doméstico, cuidado de personas, limpieza y mantenimiento, entre otras), también aumentan en casi un millón de nuevos puestos de trabajo. 
La especificidad del caso español, lo constituye el gran incremento del empleo en ocupaciones de administración y ventas, sector en donde se habrían generado casi 1.5 millones de nuevos puestos de trabajo

Salvando esta diferencia, en ambos casos, España y los Estados Unidos, se trata claramente de una polarización, en donde las ocupaciones más dinámicas, son precisamente, las que se ubican en los extremos de la estructura ocupacional. Se trata de una dinámica de crecimiento que adopta la forma de una herradura, donde los extremos crecen, y los empleos de niveles medios y directamente productivos se estancan, o simplemente decrecen en términos absolutos.

Estos datos sobre la polarización ocupacional, resulta de gran interés para nuestra discusión, pues nos permite centrar el análisis, en el impacto que la nueva economía global y flexible tiene en las ocupaciones de bajo nivel de calificación, y que corresponden a servicios personales, del cuidado, y otros, que contribuyen precisamente, a sustentar la reproducción social y cotidiana de estos nuevos profesionales, ejecutivos y directivos que genera la misma economía de la información. El incremento en el número de este tipo de ocupaciones de servicios no calificados, resulta así, en el contrapunto necesario para la expansión de las ocupaciones en la cúspide de la estructura ocupacional, los que con su alto nivel de poder adquisitivo, generan una mayor demanda de trabajo en servicios y personales, no sólo cualificados (diseñadores de interiores, servicios profesionales diversos, redes de comunicaciones y transportes, entre otros), sino también de servicios personales de baja calificación de todo tipo.

Esta polarización de las ocupaciones resulta de particular interés para nuestra discusión, pues nos ofrece el contexto estructural desde el cual analizar y comprender no solamente la inserción laboral de los inmigrantes, sino a través de ello sus contribuciones y aportes a la reproducción social de la población nativa, así como de sus estilos de vida y patrones de consumo.

\section{Migración, trabajo y reproducción social en las sociedades avanzadas}

Esta diferenciación y polarización de la estructura de ocupaciones, podemos retomarla para el entendimiento del carácter de la migración en las sociedades avanzadas, y su papel en la reproducción no sólo del capital, sino de la población nativa, y en particular, de sus estilos de vida, patrones de comportamiento y consumo, derivados del advenimiento de una sociedad postmoderna, y de la consolidación de procesos de individuación social, base de lo que Bauman ha denominado como sociedades líquidas, y que en el caso demográfico, se ejemplifica en la llamada Segunda Transición Demográfica. 
Al respecto, los datos tanto para los Estados Unidos como para España, nos permiten ilustrar esta tesis. En la siguiente gráfica, presentamos la composición del crecimiento del empleo en los extremos de la estructura ocupacional, según la condición migratoria de los trabajadores. En el caso de los Estados Unidos, vemos que en el extremo superior de la estructura ocupacional, esto es, en los trabajos de alta dirección, gerenciales, servicios profesionales y otros de similar nivel y status socioeconómico, los inmigrantes latinoamericanos prácticamente están ausentes. En efecto, entre el 2000 y el 2012, el 62\% de los nuevos empleos fueron ocupados por trabajadores nativos no latinos, a la vez que otro $18 \%$ fue ocupado por inmigrantes de otros países. Los inmigrantes latinoamericanos apenas consiguieron el $8 \%$ de esos nuevos empleos, que se suma al 12\% conseguido por los nativos de origen latino.

Figura 13

Estados Unidos y España, 2000-2012. Composición del crecimiento del empleo según origen migratorio en extremos ocupacionales

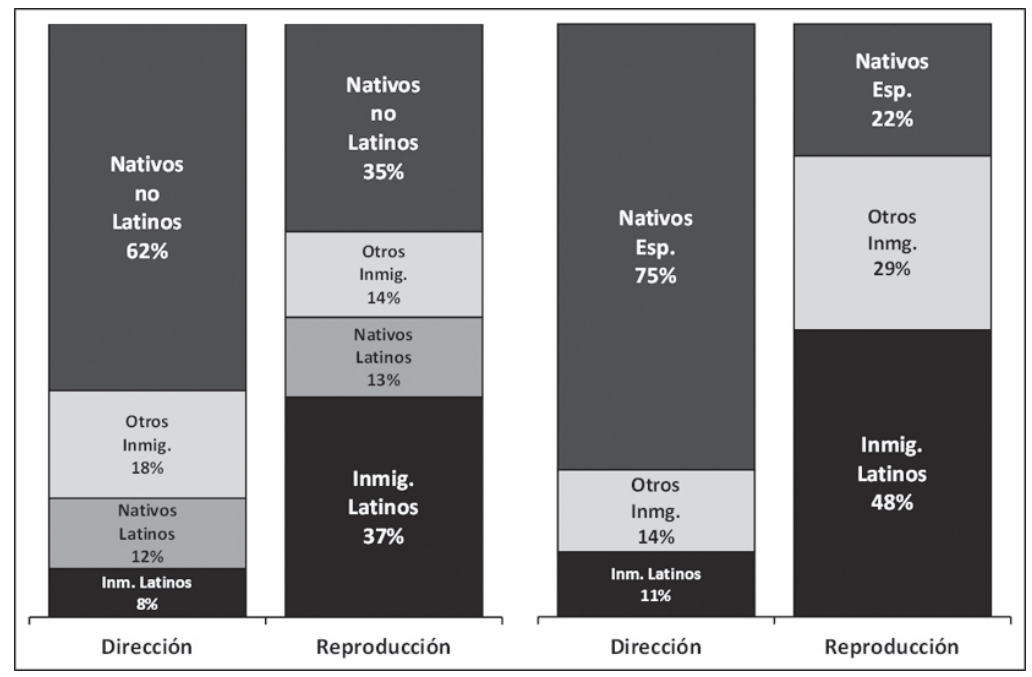

Fuentes: España, INE, Encuesta de Población Activa, 2000 y 2012 www.ine.es Estados Unidos, Buró del Censo, Current Population Survey, March Suplemment, 2000 y 2012.

Por el contrario, en el extremo inferior de la estructura ocupacional, esto es, en los trabajos dedicados a la reproducción social de la población (servicio doméstico, tareas de limpieza y mantenimiento, preparación de alimentos, cuidado de ancianos, enfermos y niños, entre otros), se da la situación inversa. Aquí, entre el 2000 y el 2012 los inmigrantes latinoamericanos, a pesar de que sólo constituyen menos del 9\% de la fuerza de tra- 
bajo, consiguieron sin embargo, el 37\% de los nuevos empleos generados en este grupo de ocupaciones, lo que los convierte en el principal grupo étnico migratorio en este tipo de actividades y puestos de trabajo. Asimismo, los trabajadores nativos no latinos, aunque constituyen el $77 \%$ de la fuerza de trabajo, sólo contribuyeron con el 35\% del empleo generado en este tipo de ocupaciones de bajo status social y económico.

En el caso de España, sucede algo similar. Por un lado, en el extremo superior de la estructura ocupacional, se tiene que prácticamente 3 de cada 4 nuevos empleos, fueron a parar a trabajadores nacidos en España, mientras que por el contrario, los inmigrantes latinoamericanos apenas consiguieron el $11 \%$ de los nuevos empleos de este tipo de ocupaciones. Por su parte, en el extremo opuesto de la estructura ocupacional, se da la situación inversa. Aquí, los españoles a pesar de constituir el 82\% de la fuerza de trabajo, sólo participaron con el 22\% de los nuevos empleos en este tipo de ocupaciones de bajo nivel y status socioeconómico. Por el contrario, los inmigrantes latinoamericanos, que aunque apenas constituyen el $8.6 \%$ de la fuerza de trabajo, consiguieron casi el $50 \%$ de los nuevos puestos de trabajo en estas ocupaciones de mayor vulnerabilidad social, precariedad e inestabilidad laboral.

Los datos aquí presentados corroboran lo que otros análisis y estudios recientes sobre la inserción laboral de los migrantes han también documentado en relación a su creciente papel en diversas actividades económicas orientadas a la reproducción social y cotidiana de la población nativa de los países de destino, particularmente la de los estratos sociales medios y altos (Vershuur, 2007). Nos referimos al amplio conjunto de ocupaciones que conforman lo que se ha llamado como servicios de proximidad, o servicios para la reproducción de la vida cotidiana, y que corresponden a aquellas actividades remuneradas que tienen por objeto satisfacer directamente, necesidades de las personas y las familias, en su ámbito doméstico, o bien que conlleven a su reproducción como personas y familias. El caso más paradigmático es el del servicio doméstico, pero no es el único. Junto a él, han proliferado muchas otras actividades y ocupaciones orientadas al cuidado de personas enfermas, niños y adultos mayores, preparación de alimentos, limpieza y mantenimiento, entre un largo etcétera.

La mercantilización del servicio doméstico y otras actividades similares, no es algo nuevo en la sociedad capitalista, lo novedoso en la situación actual, es que en los países desarrollados la masiva demanda por este tipo de trabajadores se da en el contexto de cambios sociales y demográficos que ya hemos señalado. De esta forma, el envejecimiento demográfico, la inserción masiva de la mujer al mercado de trabajo, los cambios en la formación y estructura de los hogares, la reducción de la fecundidad, entre otros, impulsan una demanda creciente por trabajadores que se dediquen a esas labores. Sin embargo, esos mismos procesos de transformación social, han derivado que los trabajadores nativos que antes se dedicaban a estas mismas labores (mujeres en el servicio doméstico y cuidado de personas, hombres en tareas de mantenimiento, preparación de alimentos y la cons- 
trucción, por ejemplo), se reducen en volumen, pues crecientemente están optando por otros trabajos menos precarizados y que gozan de mayor valoración y prestigio social, y por ende, de mejores salarios y condiciones de trabajo más dignas (Parella, 2003).

Esta situación se manifiesta en un desajuste estructural entre la demanda y oferta en este mercado de trabajo, lo que abre el espacio para que hombres y mujeres inmigrantes provenientes de países periféricos, se incorporen a este tipo de mercados en los países centrales. Nada ejemplifica mejor esta situación, que el papel de la migración en las ocupaciones orientadas a sustentar la reproducción social de la población nativa así como de sus estilos de vida y patrones de consumo.

\section{Figura 14}

\section{Estados Unidos y España, 2012. Participación de migrantes latinoa- mericanos en servicios personales específicos}

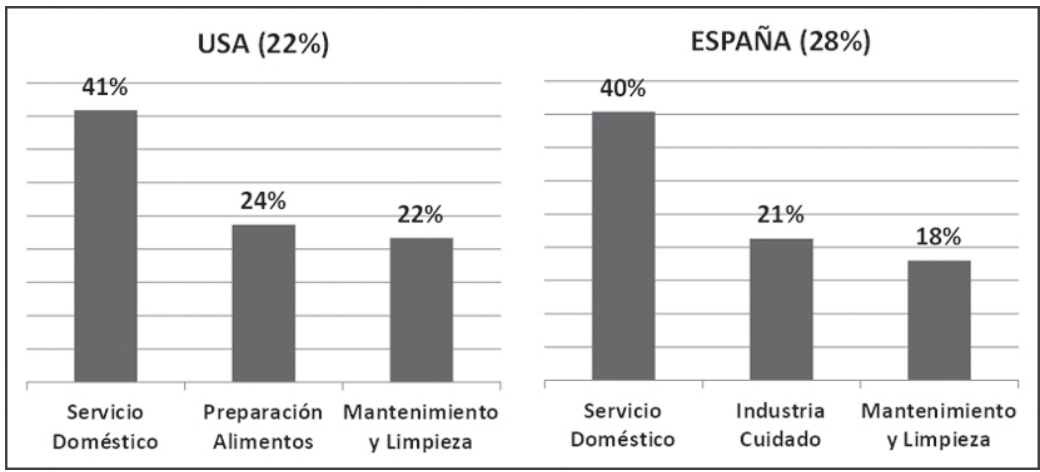

Fuentes: España, INE, Encuesta de Población Activa, 2012 www.ine.es Estados Unidos, Buró del Censo, Current Population Survey, March Suplemment, 2012.

$\mathrm{Al}$ respecto, los datos para España y los Estados Unidos son elocuentes. En el primer caso, por ejemplo, entre el 2010 y el 2012, el 28\% de los trabajadores latinoamericanos se concentraron en tan sólo 3 tipos de ocupaciones, el servicio doméstico, la industria del cuidado de personas (niños, ancianos, enfermos) y actividades de limpieza y mantenimiento. Asimismo, en estas actividades, centrales para la reproducción social y cotidiana de la población activa, los inmigrantes latinoamericanos contribuyeron con el $40 \%$ del empleo en el servicio doméstico, el $21 \%$ en la industria del cuidado y el 18\% en limpieza y mantenimiento.

En el caso de los Estados Unidos, sucede algo similar. El 22\% de los inmigrantes latinoamericanos se concentran en sólo tres tipos de ocupacio- 
nes, el servicio doméstico, la preparación de alimentos y limpieza y mantenimiento. Asimismo, y al igual que en el caso de España, los inmigrantes latinoamericanos contribuyen con el $40 \%$ del empleo en el servicio doméstico, el $24 \%$ de los trabajadores dedicados a la preparación de alimentos, y el $22 \%$ en el caso de las ocupaciones de limpieza y mantenimiento.

Estos datos ilustran el alto grado de dependencia que estas actividades y ocupaciones tienen respecto a la provisión de mano de obra latinoamericana, o lo que es lo mismo, cuan dependiente es la reproducción social y de la vida cotidiana de la población nativa, respecto a la inmigración latinoamericana.

Esta creciente demanda en los países centrales por trabajadores inmigrantes procedentes preferentemente de países del Tercer Mundo, para realizar este tipo de tareas de servicio doméstico, cuidado de personas, y en general, de los llamados servicios reproductivos y personales, conlleva una forma emergente de división social del trabajo, que adopta una forma transnacional, y que se sustenta en una forma de "trasvase de desigualdades de clase y etnia" (Parella, 2003:15), que va desde las mujeres nativas de los países centrales, que se habrían emancipado y liberado de las antiguas cadenas que las ataban a las tareas del hogar, hacia las mujeres inmigrantes que requieren de esos ingresos para su propia reproducción social, y que se ven obligadas a desatender sus propias cargas y responsabilidades reproductivas de sus familias, que se han quedado en sus países de origen ${ }^{3}$.

En este contexto, desde esta perspectiva de la reproducción social de la población de las sociedades de destino, la polarización de las ocupaciones que surge con el proceso de globalización económica, no hace sino contribuir a la configuración de diversos nichos laborales en los cuales suelen insertarse preferentemente los trabajadores migrantes. Se trata no sólo de trabajos de baja calificación laboral, sino de tareas de muy baja valoración social, lo que redunda en sus bajos salarios, contextos de precariedad, ausencia de marcos regulatorios formales, y que encierran un importante grado de desprestigio social. En este contexto, no es de extrañar entonces que surja un proceso de etnoestratificación (Catarino y Oso, 2000) o de racialización de los servicios reproductivos (Hondagneu-Sotelo, 2007), esto es, de una diferenciación socio-laboral, con base en factores étnicomigratorios, más que en las credenciales laborales de cada persona.

En este sentido, sostenemos que el análisis y entendimiento de la migración y sus contribuciones en las sociedades de destino, debiera considerar no sólo sus aspectos directamente económicos y laborales, sino también debieran enmarcarse en la profundidad de las transformaciones sociales y demográficas de estas sociedades, que surgen con la misma globalización y advenimiento de una sociedad postmoderna. Nos referimos a los procesos de individuación y que se manifiestan entre otras cosas, en la emancipación de la mujer y su creciente incorporación a los mercados de trabajo, a los cambios culturales y de comportamiento social y demográfico vinculados a la postmodernidad, al avance en la segunda transición 
demográfica, al cambio demográfico que se expresa en el envejecimiento de las poblaciones de los países desarrollados, entre muchos otros (Herrera, 2007; Beck y Beck, 2002). En este sentido, la inmigración laboral permite llenar no sólo vacíos demográficos y laborales que deja el envejecimiento, sino además sustentar estos cambios sociales y culturales de la población nativa (es lo que hemos representado en la parte central-derecha del esquema). Asimismo, la migración no sólo permite contribuir a la reproducción del capital y la economía global, sino también a la reproducción social de las clases medias y altas de las sociedades avanzadas, y en especial, sus patrones de comportamiento y estilos de vida postmodernos.

\section{Conclusiones}

En este texto hemos querido exponer con datos y argumentos, nuestra tesis de que la migración internacional puede entenderse como un fenómeno social que desde diversos ámbitos y niveles, contribuye a la estructuración de las sociedades avanzadas. En este sentido, hemos propuesto un modelo que busca analizar el papel y significado de la migración contemporánea considerando simultáneamente el conjunto de transformaciones sociales, económicas y demográficas que constituyen a las sociedades avanzadas en este mundo global y postmoderno. Con este modelo, queremos aportar en el entendimiento no sólo de la migración, sino que además, y a través de ella, en un mejor entendimiento de la sociedad contemporánea.

Sin duda, el análisis y problematización de la migración a partir de sus funciones, contribuciones, y tensiones respecto a la reproducción y estructuración de las sociedades avanzadas, puede abordarse desde los más diversos campos sociales. En nuestro caso, hemos optado por delimitar el modelo de análisis a tres ámbitos sociales, en donde podemos retomar esta mirada de la migración, a saber:

- Por un lado, considerando que la migración es ante todo, un fenómeno demográfico, resulta importante considerar su contribución en este plano, especialmente en los lugares de destino, en donde el envejecimiento de la población, está generando importantes vacíos demográficos en las edades jóvenes y de mayor capacidad productiva.

- Por otro lado, la migración contemporánea está sin duda, directamente vinculada a los procesos de globalización económica, y en particular, a la creciente segmentación y polarización de la estructura socio-ocupacional en las sociedades de destino, proceso que abre diversos nichos de mercado para la inserción laboral de los migrantes en ocupaciones de mayor precariedad laboral y vulnerabilidad social.

- Por último, esta forma de participar en la reproducción del capital, 
nos indica que los migrantes se insertan no sólo en actividades productivas, sino también en una amplia gama de servicios personales, en donde desarrollan diversas actividades que sustentan la reproducción social y cotidiana de la población de estratos medios y altos de los países de destino.

Los datos que hemos presentado en este texto, dan sustento a nuestra tesis sobre el papel de la migración internacional como campo de articulación del cambio demográfico, social y económico en sociedades avanzadas. En particular, la migración es un proceso social que a través de la articulación e integración de estos diferentes ámbitos sociales, contribuye a la actual estructuración de las sociedades avanzadas. En efecto, la migración a la vez que contribuye a subsanar el déficit de población activa que genera el envejecimiento demográfico, por ese mismo medio, aporta la fuerza de trabajo necesaria para mantener el nivel de crecimiento económico que requiere la reproducción del capital en estas sociedades. Al respecto, los datos que hemos presentado nos han permitido ilustrar cómo los migrantes hacen contribuciones significativas a la economía y demografía de los países de destino. En particular, en el caso de los Estados Unidos, por ejemplo, podemos afirmar que si en el pasado, su sostenimiento como una economía imperial se sustentaba en sus propias fuerzas productivas (mano de obra nativa), hoy en día, la demografía de ese país no asegura ya la reproducción de la fuerza de trabajo necesaria para mantener ese nivel de desarrollo de las fuerzas productivas del capital, generando un déficit de mano de obra que de no cubrirse con inmigración, no sólo afectaría el crecimiento económico de ese país, sino por sobre todo, su capacidad para mantener el liderazgo político y militar necesario para sustentar sus posiciones imperialistas.

Asimismo, como hemos señalado tanto para el caso de España como de los Estados Unidos, la inmigración laboral no se refiere a trabajadores así en abstracto, sino a una mano de obra muy específica, y que se emplea preferentemente en diversas tareas vinculadas a la reproducción social de la población nativa. Este dato no es menor, pues este patrón de inserción ocupacional de los inmigrantes contribuye directamente no sólo a la reproducción económica de los países de destino, sino por sobre ello, a la reproducción social de su población nativa, y de sus patrones de consumo de alto nivel, propios de un estilo de vida postmoderno. Así por ejemplo, en cierta medida, la emancipación de la mujer de sus tareas domésticas, es en realidad un trasvase de esas actividades hacia trabajadoras inmigrantes. En otras palabras, mientras las mujeres de clases medias y altas de las sociedades de destino avanzan en su proceso de individuación y liberación, las tareas domésticas y de reproducción (servicio doméstico, cuidado de personas, preparación de alimentos, entre otras), recaen en estas trabajadoras inmigrantes, reproduciendo así, nuevas formas de desigualdad social, que articulan simultáneamente, las condiciones de clase, género y etnia.

Este análisis desde la perspectiva de la reproducción de la sociedad, nos permite leer e interpretar la migración internacional con base en otros 
significados sociales, económicos, demográficos y culturales. Si por un lado, la migración es un factor que contribuye a la reproducción de la sociedad contemporánea, por otro lado, y con base en esa misma contribución, la migración también constituye un factor que contribuye a la transformación de esa misma sociedad.

Nada ejemplifica mejor esta situación que el papel de la migración para enfrentar los desafíos demográficos que impone el envejecimiento de la población en las sociedades de destino. Como hemos señalado en este texto, el envejecimiento y decline demográfico, hacen que actualmente tanto la dinámica económica de los países desarrollados, como la reproducción social de su población, dependan directamente de los aportes demográficos que hace la inmigración, especialmente aquella proveniente de los países del Tercer Mundo. Sin embargo, estos mismos procesos demográficos, propician que esta inmigración derive en una profunda transformación de la composición étnica de la población de los países centrales.

En el caso de los Estados Unidos, por ejemplo, informes recientes del Departamento de Salud de ese país, indican que actualmente sólo el $50 \%$ de los nacimientos corresponden a hijos de madres blancas no latinas, mientras que el 25\% de los nacimientos, corresponden a madres de origen latino, y el otro 25\% a madres de otras minorías étnicas y migratorias. Estos datos prefiguran la dimensión y magnitud del cambio en la composición de la población de ese país, según su origen étnico y migratorio. Si a ello agregamos que los niveles de fecundidad de la población latina superan con creces al de la población nativa (la cual incluso está ligeramente por debajo de los niveles de reproducción demográfica), el cambio demográfico que viene adquiere niveles de gran importancia, que cuestionará directamente los actuales equilibrios políticos y sociales sustentados en una estructura demográfica que está transformándose aceleradamente.

Esta es la contradicción que se plantea en los países centrales frente a este régimen global de reproducción demográfica. Por un lado, ante el envejecimiento que se vive en esos países, la inmigración permite dar sustentabilidad demográfica a la reproducción social y económica de sus poblaciones. Pero simultáneamente, la conjunción de ambos procesos, envejecimiento e inmigración, es lo que ha dado origen a esta transformación de la composición étnica y demográfica de las poblaciones del primer mundo. En otras palabras, en los países centrales, para reproducirse socialmente, necesitan transformarse demográficamente. El problema está en que no se trata de cualquier cambio demográfico, sino de uno que conlleva el cuestionamiento y erosión de las bases que sustentan las actuales hegemonías demográficas que se quieren reproducir (de clase, étnicas, generacionales, entre otras).

En este marco, podemos entender la profundidad y trascendencia histórica del dilema que enfrentan actualmente los países del Primer Mundo, a saber: o bien se asegura el proceso de reproducción social y económica con base en la adopción de una política de apertura y tolerancia a la 
inmigración, pero que conlleva, sin embargo, una profunda transformación étnico y cultural de su población, o bien se adopta una política radical de control y freno a la inmigración masiva, pero a riesgo de entrar en un proceso de insustentabilidad demográfica que pondría en riesgo no sólo la estabilidad poblacional, sino también la estabilidad económica y social de esos países.

Se trata de un dilema de naturaleza demográfica pero que tiene decisivas implicaciones económicas, sociales y políticas. Su importancia radica en los impactos que tendría una reducción de la población activa sobre el desarrollo de las fuerzas productivas y económicas de los países centrales. En otras palabras, de no mantenerse esta inmigración y transformación étnica de la población, la misma economía, junto con la demografía y la estructura social de esos países, se verían seriamente comprometidas. 


\section{Notas}

${ }^{1}$ Como un componente importante de este proceso de individualización, se sitúa la emancipación femenina, que ha derivado en la promoción de un contexto con mayor equidad de género, abriendo diversos espacios para la participación de las mujeres en la vida pública, laboral, social, educativa, así como también en la recomposición de los roles de género al interior de los espacios privados del hogar, la familia y de la vida cotidiana (Beck y Beck, 2002).

${ }^{2}$ El modelo se basa en las siguientes ecuaciones:

(1) $\mathrm{PIB}^{\mathrm{M}}=\operatorname{SUMA}\left(\mathrm{PIB}^{\mathrm{M}}\right.$ )

Donde: PIB ${ }^{\mathrm{M}}$ es el PIB total generado por los trabajadores mexicanos en Estados Unidos, y $\mathrm{PIB}^{\mathrm{M}}$ es el PIB generado por los trabajadores mexicanos en el sector "i”"

(2) $\mathrm{PIB}_{\mathrm{i}}^{\mathrm{M}}=\mathrm{PME}_{\mathrm{i}} * \mathrm{~L}_{\mathrm{i}}^{\mathrm{M}}$

(3) $\mathrm{PME}_{\mathrm{i}}=\mathrm{PIB}_{\mathrm{i}} / \mathrm{L}_{\mathrm{i}}$

Donde: $P M E_{i}$ es la productividad media en el sector " $\mathrm{i}$ ”; $\mathrm{L}_{\mathrm{i}}^{\mathrm{M}}$ es la fuerza de trabajo migrante (mexicanos) ocupados en el sector "i”; PIB ${ }_{i}$ es el PIB del sector "i”, y $\mathrm{L}_{\mathrm{i}}$ es la fuerza de trabajo total ocupada en el sector "i”. Con estas ecuaciones, el PIB generado por la fuerza de trabajo mexicana migrante en Estados Unidos se calcularía de la siguiente forma:

(4) $\mathrm{PIB}^{\mathrm{M}}=\mathrm{PME}_{1} * \mathrm{~L}_{1}^{\mathrm{M}}+\mathrm{PME}_{2} * \mathrm{~L}_{2}^{\mathrm{M}}+\ldots+\mathrm{PME}_{34} * \mathrm{~L}_{34}^{\mathrm{M}}$

Cabe señalar que la estimación es válida para el PIB total generado por los trabajadores mexicanos, pero no lo sería para cada sector por separado, pues en ese caso el tamaño de la muestra y los supuestos subyacentes no lo permiten.

${ }^{3}$ Aunque este no es el momento para entrar en el debate, no podemos pasar por alto, la paradoja que implica todo este proceso de emancipación de la mujer en los países centrales. $\mathrm{Al}$ respecto, lo menos que podemos decir, es que se trata de una emancipación fragmentada y que reproduce formas de desigualdad social y de género. Sin duda, favorece en algunos aspectos a las mujeres de los países centrales, pero no rompe necesariamente con la inequidad de género en esos mismos países. Esta desigualdad tan sólo habría sido transferida desde las mujeres nativas hacia las mujeres inmigrantes. En el fondo, la liberación de unas (las mujeres nativas), así sea parcial e incompleta, descansa en cierta forma, en la opresión de otras (las mujeres inmigrantes). 


\section{Bibliografía}

Bauman, Zygmunt (2011), Daños colaterales. Desigualdades sociales en la era global. Fondo de Cultura Económica, Buenos Aires.

Ídem (2003), Modernidad líquida. Fondo de Cultura Económica, Argentina.

Beck, Ulrich (2000), Un nuevo mundo feliz. La precariedad del trabajo en la era de la globalización. Editorial Paidós, Barcelona.

Beck, Ulrich y Elisabeth Beck-Gernshmein (2002), Individualization, SAGE Publications, Londres.

Bongaarts, J. (2001), “Fertility and reproductive preferences in posttransitional societies”. Pp. 260-282, in: R. A. Bulatao and J. B. Casterline (eds), Global Fertility Transition, Supplement to Population and Development Review, Vol. 27, Population Council, New York.

Borjas, George J. (2001), Heaven's Door: Immigration Policy and the American Economy. Princeton, Princeton University Press.

Canales, Alejandro I. (2011), “Las profundas contribuciones de la migración latinoamericana a los Estados Unidos”. En Jorge Martínez Pizarro (Editor) Migración internacional en América Latina y el Caribe. Nuevas tendencias, nuevos enfoques. CEPAL, páginas 257-331, LC/R.2170, Santiago, Chile.

Castells, Manuel (1998), La era de la información. Economía, sociedad y cultura. Vol. 1. La sociedad red. España. Alianza Editorial.

Catarino, Christine y Laura Oso (2000), “La inmigración femenina en Madrid y Lisboa: hacia una etnización del servicio doméstico y de las empresas de limpieza”. PAPERS, Revista de Sociología, No. 60. Pp. 183-207. Universidad Autónoma de Barcelona.

Cooke, M. (2003), "Population and Labour Force Ageing in Six Countries”, in Workforce Aging in the New Economy, Working Paper (4).

De la Garza, Enrique (1998), “El concepto de economía y su transformación”. En Enrique de la Garza (coordinador), Ciencia económica. Transformación de conceptos. Siglo XXI Editores y UNAM, Centro de Investigaciones Interdisciplinarias en Ciencias y Humanidades, México.

Herrera Ponce, María Soledad (2007), Individualización social y cambios demográficos: ¿hacia una segunda transición demográfica?. Centro de Investigaciones Sociológicas, Colección monografías, No. 232, Madrid.

Hobbs, Frank y Nicole Stoops (2002), Demographic Trends in the 20th 
Century, Census 2000 Special Reports 4, US Census Bureau.

Hobsbawm, Eric (2000), Entrevista sobre el siglo XXI, Editorial Crítica, Barcelona.

Hondagneu-Sotelo, Pierrete (2007), Doméstica: Immigrant Workers Cleaning and caring in the Shadows of Affluence. University of California Press, Los Angeles.

Kumar, Kishan (1995), From Post-Industrial to Post-Modern Society. New Theories of the Contemporary World. Blackwell Publishers Ltd., Massachusetts.

Lipietz, Alain (1997), El mundo del post-fordismo. Cuadernos del CUSCH. Universidad de Guadalajara. Jalisco, México. Disponible en línea: http:// www.revistas.unal.edu.co/index.php/ede/article/viewFile/23729/24410

Martin, Philip (2002), “Mexican Workers and U.S. Agriculture: The Revolving Door.” International Migration Review; Vol. 36, No. 4.

Parella Rubio, Sonia (2003), Mujer, inmigrante y trabajadora: la triple discriminación. Editorial Anthropos, España.

Piore, Michael (1979), Birds of Passage. Cambridge University Press, Cambridge.

Ruhs, Martin y Phillip Martin (2008), “Numbers vs. Rights: Trade-offs and Guest Worker Programs”, International Migration Review, vol. 42, 1, pp. 249-265, Center for Migration Studies, Nueva York.

Sassen, Saskia (2007), Una sociología de la globalización, Katz Editores, Buenos Aires.

Smith, James P. and Barry Edmonston, Editors (1997), The New Americans: Economic, Demographic, and Fiscal Effects of Immigration. Panel on the Demographic and Economic Impacts of Immigration, National Research Council, Estados Unidos.

Van de Kaa, Dirk (2002), “The idea of a Second Demographic Transition in Industrialized Countries.” Paper presented at the Sixth Welfare Policy Seminar of the National Institute of Population and Social Security, Tokyo, Japan, 29 January. Disponible en línea http://www.ipss.go.jp/webj-ad/ webjournal.files/population/2003_4/kaa.pdf Consultado 10 de enero de 2013.

Van de Kaa, Dirk (1987), “Europe’s second demographic transition”. Population Bulletin, 42(1).

Vershuur, Christine (2007), “Inmigrantes y nueva división internacional 
del trabajo y de los cuidados”. En Isabel Yépes del Castillo y Gioconda Herrera (Editoras.) Nuevas migraciones latinoamericanas a Europa Balances y desafíos. FLACSO Ecuador, OBREAL, GRIAL y Universidad de Barcelona.

Recibido: 20.07.2013

Aceptado: 31.07.2013 